\title{
QTL Underlying Reniform Nematode Resistance in Soybean Cultivar Hartwig
}

\author{
Yi-Chen Lee ${ }^{1,2}$, David A. Lightfoot ${ }^{1,2}$, James Anderson ${ }^{1,2}$, Robert T. Robbins ${ }^{3}$, and Stella K. Kan- \\ $\operatorname{tartzi}^{1,2, *}$
}

1 Plant Biotechnology and Genomics Core-Facility, Department of Plant, Soil, and Agricultural Systems, Southern Illinois University, Carbondale, IL 62901; ${ }^{2}$ The Illinois Soybean Center (Center for Excellence in Soybean Research, Teaching and Outreach), Southern Illinois University, Carbondale, IL 62901; ${ }^{3}$ Department of Plant Pathology, Cralley-Warren Research Center, University of Arkansas, Fayetteville, AR 72701.

Received: September 17, 2016 / Accepted: December 1, 2016

\section{Abstract}

Nematodes are one of the most destructive plant-parasitic pests in soybeans [Glycine max (L.) Merrill]. Among the nematodes, soybean cyst nematode (SCN, Heterodera glycines Ichinohe), southern root-knot nematode [RKN, Meloidogyne incognita (Kofoid and White) Chitwood], and reniform nematode (RN, Rotylenchlus reniformis Linford and Oliveria) are often the most problematic in soybean yield production. The plant introduction PI437654 has been used previously to map RN quantitative trait loci (QTL). However, 'PI437654' is non-domesticated. 'Hartwig' was the first domesticated cultivar to introgress some of the resistances from PI437654. The aims here were to map QTL underlying $R N$ resistance in Hartwig. A cross between Flyer and Hartwig $(n=92)$ was created to map QTL that underlie both $S C N$ and $R N$ resistance. The $\mathrm{F} \times \mathrm{H}$ population was phenotyped at the nematology lab at the University of Arkansas in 2014 and 2015 The F $\times$ H was genotyped with 140 polymorphic microsatellite markers (simple sequence repeats, SSR). In this study, 4 SSRs were highly significant $(P<0.001)$ associated by ANOVA and composite interval mapping and each were determined to identify a QTL. There were QTL on Chr. 12 (LG H, Satt353), and 3 on Chr. 18 (LG G, Satt275, Satt163, and Satt309). The beneficial alleles all derived from Hartwig. Satt353 has previously been reported to link to sudden death syndrome (SDS) QTL, and all three Satt markers on LG $\mathbf{G}$ have been reported to link to rhg 1.Therefore, Hartwig and cultivars derived from it ('Anand', 'Ina') may be used to address the growing RN problems.

Keywords: Soybean, reniform nematode, resistance, Hartwig.
Introduction

Nematodes are one of the most destructive plant-parasitic pests in soybeans [Glycine $\max$ (L.) Merrill]. Among nematodes, soybean cyst nematode (SCN, Heterodera glycines Ichinohe), southern root-knot nematode [RKN, Meloidogyne incognita (Kofoid and White) Chitwood], and reniform nematode (RN, Rotylenchlus reniformis Linford and Oliveria) are often the most problematic in soybean yield production (Robbin et al. 1994a; Koenning and Wrather 2010). Nematode management options include nematicide application, rotation with non-host crop, and the use of resistant cultivars (Jiao et al. 2015; Lee et al. 2015). An estimation of $\$ 1$ billion loss annually due to $\mathrm{SCN}$ has been reported (Wrather and Koenning 2009), therefore breeding SCN resistant cultivars has been the top priority. However, the continuous breeding for SCN resistant cultivars may accelerate selection for other nematode pests, hence breeding cultivars with multiple nematode resistance is crucial (Schmitt and Barker 1988; Lee et al. 2015). Many cultivars that are resistant to SCN but not RKN or RN have been reported. Studies have shown that SCNresistant soybean cultivars that derive resistance from 'Peking' (like 'Forrest') and 'PI 437654' (like 'Hartwig') are potentially resistant to RN whereas resistance derived from 'PI88788' are not (Caviness and Riggs 1976; Robbins el al. 1994a, 1994b; Davis et al. 1996; Robbins and Rakes 1996; Jiao et al. 2015). This indicates that there is a common or linked gene controlling the resistant for both $\mathrm{SCN}$ and $\mathrm{RN}$ at or near the rhg la allele (Ha et al. 2007) but not the rhg $1 \mathrm{~b}$ allele.

The RN was first observed in Hawaii on cowpea roots in 1931 (Robbins et al. 1999). RN was originally considered to be a tropical nematode pest but has since spread to the eastern half of the U.S. cotton belt, the RN has since become a major pest in

*Corresponding author: stella.kantartzi@siu.edu

ATLOS Publishing, LP

This is an Open Access article distributed under the terms of the Creative Commons Attribution License (http://creativecommons.org/licenses/by/3.0/), which permits unrestricted use, distribution, and reproduction in any medium, provided the original work is properly cited. 
tropical, sub-tropical, and southern United States (Robbins et al. 1999; Jones et al. 2015). The RN host range includes up to 77 plant families, in the United States, common hosts include upland cotton, soybean, and pineapple (Robinson et al. 2007; Wubben et al. 2015). Cotton yield lost due to RN infection could be greater than $\$ 100$ million annually and soybean losses could exceed that in future (Blasingame and Patel 2012).

Numerous soybean breeding lines and cultivars have been tested for RN reproduction, resistance, and susceptibility, including lines from the Arkansas and Mississippi Soybean Variety Testing program and lines submitted from extension nematologist (Robbins et al. 1994; Robbins et al. 2002). In addition, the genetic approach has been researched extensively to understand the quantitative trait loci (QTL) responsible for the resistance. Two QTL have been reported in a cross between 'BSR 101' and PI 437654, on Chromosome 11 (Chr. 11, Linkage group B1) and Chr. 19 (LG L), using restriction fragment length polymorphisms, by Pioneer Hi-Bred International, Inc in 2000 (unpublished study). Ha et al. (2007) reported two additional QTL in the BSR $101 \times$ PI 437654 population Chr. 1 and Chr. 18 (LG B 1, Satt359 and LG G, Sat_168) using simple sequence repeat markers (SSR). In addition, the positions of QTL previously identified by Pioneer Hi-Bred International, Inc were refined (Chr. 19; LG L, Sat_184 and Satt513). Jiao et al. (2015) reported two additional QTL on Chr. 18 (LG G, BARC-021459-04106) and Chr. 11 (LG B1, BARC-012237-01756). The PI437654, though non-domesticated and viney, has been used as a source to introgress neamatode resistances to domesticated cultivars including Hartwig, 'Anand' and 'Ina' (Kazi et al., 2008; 2010).

A cross between 'Flyer' and Hartwig $(n=92)$ was created to map QTL that underlie SCN resistance (Kazi et al. 2005; 2010). This population was used here to identify QTL that underlie resistance to RN. Hartwig derives parts of its SCN, RKN and RN resistances from the non-domesticated PI437654 but does so in a domesticated (Forrest like) plant phenotype. The $\mathrm{F} \times \mathrm{H}$ population was phenotyped at the nematology lab at the University of Arkansas in 2014 and 2015. The $\mathrm{F} \times \mathrm{H}$ population was genotyped with 140 polymorphic SSR markers (Schultz 2007; Kazi et al 2010). Here the following is reported, 12 SSRs were identified to be significantly associated with the RN resistance trait, 5 out of the 12 SSRs were highly significant $(P<0.001)$ and were determined to identify QTL, This study further supports that there are common QTL or genomic regions controlling both $\mathrm{SCN}$ and $\mathrm{RN}$ resistance.

\section{Materials and Methods}

\section{Plant Material}

The genetic material used in this study consisted of the $\mathrm{F} \times \mathrm{H}$ recombinant inbred lines (RILs; $n=92$; Yuan et al. 2002; Kazi et al. 2007; 2008; 2009). Populations were advanced to the F5:14 from 2003 to 2005 and seed were released in 2007 (Kazi et al. 2007). The population was increased every 4 years since then and is now at the F5:16. The cross was selected because it showed segregation for seed yield and many pest resistances, including well characterized reactions to SDS, RKN, RN and SCN. Hartwig was lower yielding but consistently resistant to nematode diseases and SDS in most locations (Wrather et al. 1995; Niiti et al. 1997; 2001; Mueller et al. 2002; Kazi et al. 2010). It was strongly resistant to most HG Types of SCN, RKN and RN (Anand 1992; Niblack et al. 2003). Flyer was higher yielding and resistant to phytophtora root rots but susceptible to most nematodes and to SDS (McBlain et al. 1990; Niiti et al. 1997; 2001; Yuan et al. 2002; Kazi 2005; et al. 2008).

\section{Reniform Assay}

The $\mathrm{F} \times \mathrm{H}$ population was sent to the Nematology Laboratory at the University of Arkansas for reniform nematode assay, the assay is modified from Robbins et al. 1994. The soil used in the study was fine sandy loam from the Arkansas River, with a maximum of $4 \%$ clay, $85 \%$ sand and the rest was silt. The plants were germinated in vermiculite and transplanted to 8 ounce Styrofoam ${ }^{T M}$ coffee cups with drain holes at the cotyledon stage, and inoculated with 2,000 vermiform reniform nematodes on the same day. The assay included 5 repetitions per lines and the randomized complete block design (RCBD) was used in the study. To separate the resistant and susceptible lines more efficiently, the duration of the assay was set at 10 to 12 weeks. Flyer, 'Braxton', and 'Ellis' were used as the susceptible checks and Hartwig, and Anand were used as the resistant checks. The plants were set out to dry for 3 to 4 days before harvest, the soybean roots were discarded and the number of reniform nematodes in the soil were counted. The average of the reniform nematode number on roots was calculated from the 5 repetition for each line. The data was converted into reproductive index, described as the average divided by the original inoculation (average/2000, RI). The assay was carried out in 2014 and 2015. The average of the RI from the two years was calculated.

\section{Data Analysis}

The $\mathrm{F} \times \mathrm{H}$ population was screened with 600 SSR markers, 140 SSR markers were selected based on the polymorphisms. The RIL lines were scored by the genotypes. RI was used as the phenotypic trait for QTL mapping. A one-way ANOVA was performed by using JMP 12 statistic software (JMP ${ }^{\circledR}$, Version 12, SAS Institute Inc, NC, USA). The mean, standard error, and student- $t$ test $(P<0.05)$ was recorded. Composite interval mapping was used to confirm the QTL.

\section{Results}

\section{Polymorphism and Linkage}

The linkage map used is described in Kazi et al. (2008; 2010). Briefly, one hundred and forty two markers were found to be polymorphic within a Flyer $\times$ Hartwig $(F \times H)$ RIL population. There were 3-10 markers per linkage group and distance between markers was 10-25 cM except for LG G (Meksem et al. 1999) and $K$ that were tested with additional markers due to previous discoveries of SCN resistance, SDS resistance and seed yield QTL (Yuan et al. 2002; Kazi et al. 2008). Sixty one mark- 
ers of the markers formed 17 linkage groups encompassing 534 cM. Assuming $10 \mathrm{cM}$ as a distance for QTL detection, the groups formed plus the 81 unlinked markers would allow the detection of QTL over 2,494 cM. The recombination distances and orders of markers in linkage groups (with 2-3 exceptions) and genome size (2,512 cM) agreed with those reported (Song et al. 2004).

\section{Variation of Resistance Within F $\times$ H RILs to RN}

The means and standard errors of phenotypic variation of RI among the two parents and RILs within RI data from both years were normal (Fig. 1) indicating that the RN bioassays were useful for further analysis. Transgressive segregation was observed in RI scores. The RIL population mean was intermediate to the two parents for each HG Type. Narrow sense heritability estimates for $\mathrm{RI}$ had relatively high values $(0.95,0.96)$ in both years.

\section{Correlations With SCN Trait Data}

There was a significant positive correlation with resistance to $\mathrm{SCN}\left(\mathrm{P}<0.05\right.$; $\mathrm{R}^{2}$ was just $\left.11 \%\right)$. Interestingly the correlation with susceptibility to SDS was significant $\left(P<0.05 ; R^{2}\right.$ was $\left.-27 \%\right)$. This is inverse to the correlation between SDS and SCN $(P<0.05$; $\mathrm{R}^{2} 56 \%$ ).

\section{DNA Marker Analysis}

Among the 140 markers only 12 SSRs with significant association were detected (Fig. 2; Table 1). The 11 SSR markers were detected on Chr. 2 (LG DIb), Chr. 5 (LG Al), Chr. 8 (LG A2), Chr. 12 (LG H), and Chr. 18 (LG G). Seven QTL had a $P$ value greater than 0.001 , whereas 4 QTL had $P$ value less than 0.001 (highly significant). Satt353 was detected on Chr. $12\left(P\right.$ value $\left.=0.0076, R^{2}=10 \%\right)(L G H$, Start position $1,682,557$ end position $1,682,607)$, and the beneficial allele derived from

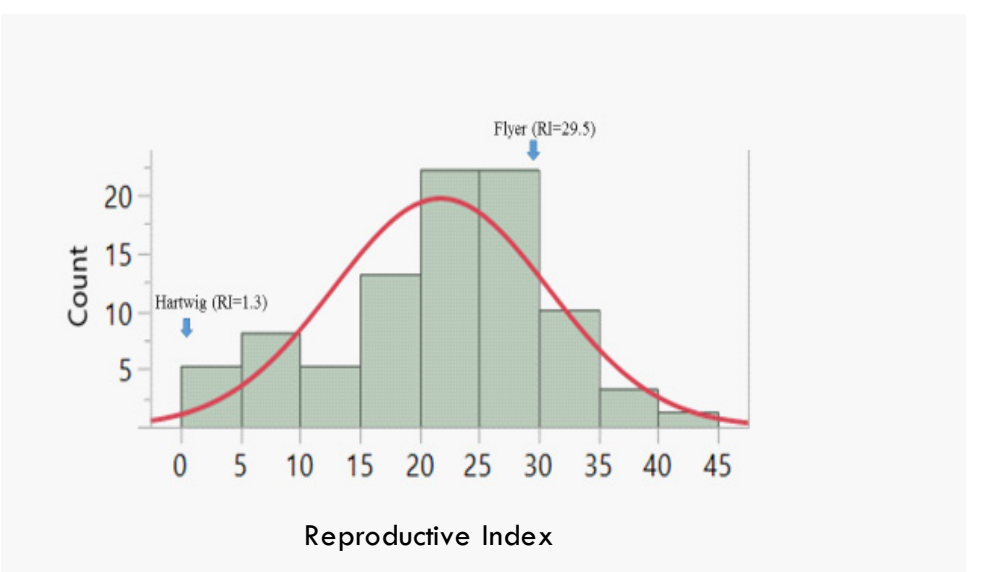

Fig. 1. Trait distribution for RN showing parental scores and limited transgressive segregation.

Table 1. Potential QTL underlying resistance to RN.

\begin{tabular}{lllllll}
\hline \multicolumn{7}{c}{ RI } \\
Marker & Chr & LG & Mean & $\begin{array}{l}\text { Hartwig } \\
\text { Mean }\end{array}$ & P>F & R $^{2}$ \\
\hline Satt537 & 2 & D1b & $20.0 \pm 1.3$ & $23.9 \pm 1.4$ & 0.038 & 0.053 \\
Satt428 & 2 & D1b & $19.9 \pm 1.3$ & $24.3 \pm 1.5$ & 0.027 & 0.066 \\
Satt599 & 5 & A1 & $19.7 \pm 1.7$ & $25.5 \pm 1.5$ & 0.014 & 0.11 \\
B61P08b & 8 & A2 & $24.1 \pm 1.4$ & $19.2 \pm 1.7$ & 0.03 & 0.07 \\
Satt353 & 12 & H & $18.1 \pm 1.5$ & $24.1 \pm 1.5$ & 0.0076 & 0.1 \\
Satt181 & 12 & H & $19.3 \pm 1.4$ & $24.4 \pm 1.8$ & 0.02 & 0.078 \\
Satt275 & 18 & G & $24.7 \pm 1.2$ & $19.2 \pm 1.5$ & 0.0084 & 0.1 \\
Satt163 & 18 & G & $24.1 \pm 1.1$ & $16.5 \pm 2.0$ & 0.0028 & 0.135 \\
Satt309 & 18 & G & $24.1 \pm 1.0$ & $16.4 \pm 2.0$ & 0.0044 & 0.132 \\
TMD1 & 18 & G & $24.1 \pm 1.1$ & $17.6 \pm 2.0$ & 0.0134 & 0.1 \\
Satt610 & 18 & G & $24.6 \pm 1.6$ & $18.9 \pm 1.9$ & 0.033 & 0.089 \\
\hline
\end{tabular}



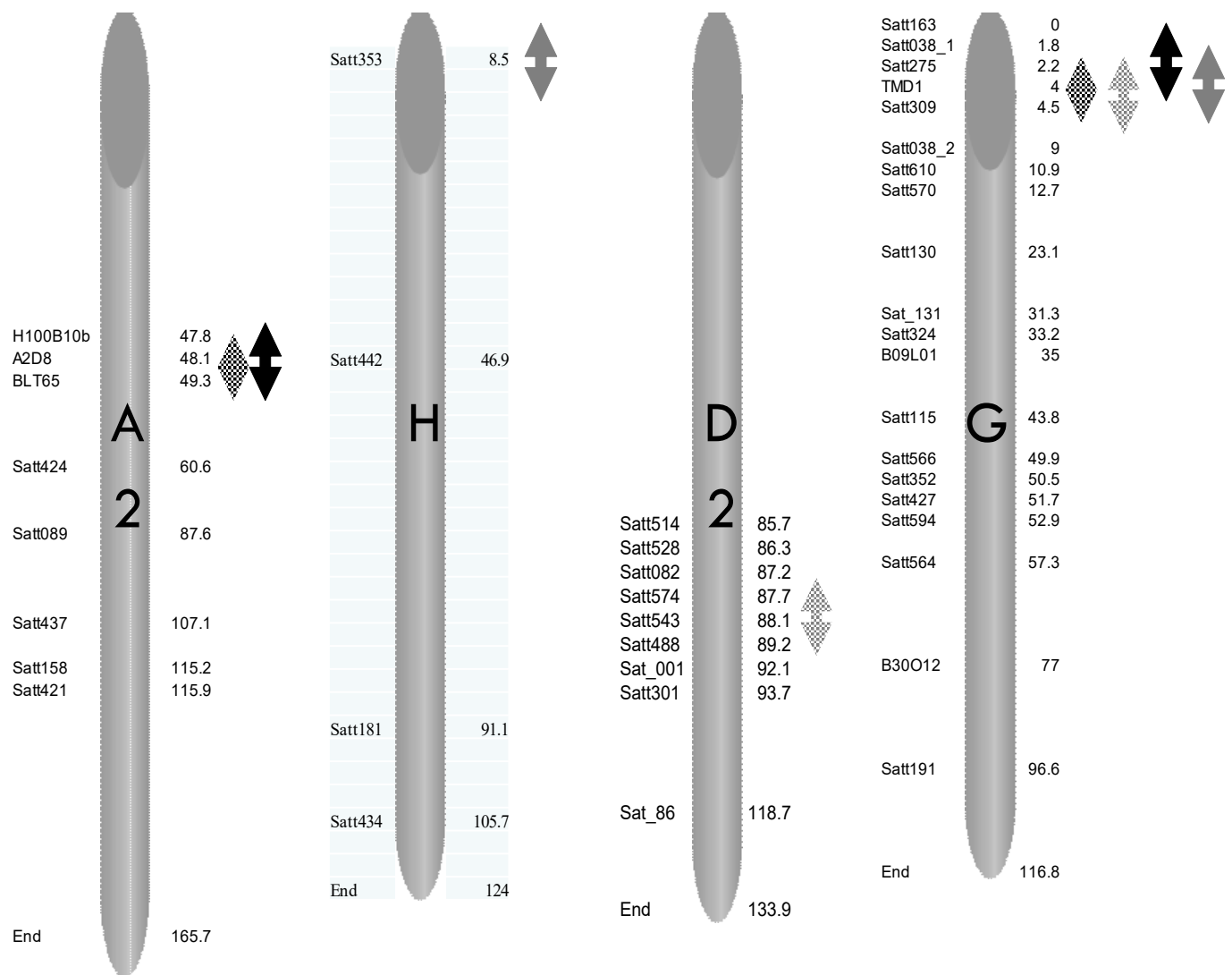

Fig. 2. Linkage groups with significant QTL underlying resistance to SCN Hg Types (black and stippled arrows) and RN (grey arrows) by ANOVA and composite interval mapping.

Flyer. The 3 markers on Chr. 18 (LG G) has previously been reported to link to SCN 41-1, which is resistant to HG type 0 (Kazi et al. 2010). The beneficial allele for all 3 markers derived from 'Hartwig'. Satt 163 was the most significantly associated with the trait $\left(P\right.$ value $\left.=0.0028, R^{2}=13.5 \%\right)$, followed by Satt309 $(P$ $\left.=0.0044 R^{2}=13.2 \%\right)$, the least significant on LG $G$ was Satt 275 $\left(P=0.0084, R^{2}=10 \%\right)$. Satt275 has been reported to be linked to Satt309.

\section{Discussion}

The three Satt markers found on LG G had all been previously reported to be linked with SCN QTL near rhg 1 in the $\mathrm{F} \times \mathrm{H}$ population, Satt275 linked to SCN $41-1$, Satt 163 and Satt 309 linked to SCN 41-2 (Kazi et al. 2010). In addition, Satt309 was very closely linked to $R f_{s} 2 / r h g 1$ allele $a$ in the Essex $\times$ Forrest population (Meksem et al. 1999). The, rhg 1 resistance alleles a and $b$ are required for all known HG type resistances to SCN. However, only allele a appears to give resistance to RN (Caviness and Riggs 1976; Robbins el al. 1994a, 1994b; Davis et al. 1996; Robbins and Rakes 1996; Jiao et al. 2015). These findings infer that reniform resistance QTL maybe closely linked to or pleiotropic with some of the genes underlying $\mathrm{SCN}$ resistance QTL (Cook et al 2012; Srour et al 2012).

The findings here on rhg 1 agree with previous studies ( $\mathrm{Ha}$ et al. 2007) so are unlikely to be errors. Which of the genes implicated in SCN resistance (Cook et al.2012; Srour et al. 2012) also contributes to $\mathrm{RN}$ resistance, if any, will be the focus of future work with near isogeneic lines and transgenic lines (Kazi et al. 2005; Lightfoot 2015). Based on linkage data, and correlations among $\mathrm{RN}, \mathrm{SCN}$ and SDS traits it may be inferred the $\mathrm{RN}$ resistance gene(s) is or are linked to $\operatorname{rhg} 1$ and $R f s 2$ on the telomeric side but at some distance.

The one additional locus or QTL, on Chr. 12 (LG H, Satt353), had not been reported by 2016. Many, but not all nematode resistance loci are found in cultivars derived from PI437654 (Vierling et al. 1996; Webb et al. 1996) like Hartwig (Kazi et al. 2010). The PI has superior resistance to cultivars derived from it. It may be hypothesized that the plant introduction contains many more resistance genes to nematodes than were yet discovered. Since Hartwig was parent to Ina and Anand, and many other cultivars, the QTL reported here may improve selections for resistance to $\mathrm{RN}$ for many breeding programs.

\section{Acknowledgements}

This research was funded by grants from the United Soybean Board to SK and RR; and the family of YCL. The authors thank Dr. P. Gibson, O. Myers Jr. and M. Schmidt for assistance with germplasm development and maintenance from 1991-2000. We thank J.H. Klein III for assistance with germplasm maintenance from 1991-2011. We thank Ted Ballard for assistance with the population from 2012 to present. 


\section{References}

Anand SC (1992) Registration of 'Hartwig' soybean. Crop Sci 32:1 294.

Caviness C, Riggs RD (1976) Breeding for nematode resistance. Proc World Soybean Res Conf 1975: 594-601.

Cook DE, Lee TG, Guo X, Melito S, Wang K, Bayless AM, Wang J, Hughes TJ, Willis DK, Clemente TE, Diers BW, Jiang J, Hudson ME, Bent AF (2012). Copy number variation of multiple genes at Rhg 1 mediates nematode resistance in soybean. Science 338: 12061209.

Davis EL, Koenning SR, Burton JW, Barker KR (1996) Greenhouse evaluation of selected soybean germplasm for resistance to North Carolina populations of Heterodera glycines, Rotylenchulus reniformis, and Meloidogyne species. J Nematol 28: 590-598.

Ha B-K, Robbins RT, Han F, Hussey RS, Soper JF, Boerma HR (2007) SSR mapping and confirmation of soybean QTL from PI 437654 conditioning resistance to reniform nematode. Crop Sci 47: 1336-1343.

Jiao Y, Vuong TD, Liu Y, Li Z, Noe J, Robbins RT, Joshi T, Xu D, Shannon JG, Nguyen HT (2015) Identification of quantitative trait loci underlying resistance to southern root-knot and reniform nematodes in soybean accession PI 567516C. Mol Breeding 35: 131.

JMP®, Version 12. SAS Institute Inc., Cary, NC, 1989-2016.

Jones JT, Haegeman A, Danchin EGJ, Gaur HS, Helder J, Jones, MGK, Kikuchi T, Manzanilla-López R, Palomares-Rius JE, Wesemael WML, Perry RN (2013) Top 10 plant parasitic nematodes in molecular plant pathology. Mol Plant Path 14 (9): 946-961.

Kazi S (2005) Minimum tile derive microsatellite markers improve the physical map of the soybean genome and the Flyer by Hartwig genetic map at Rhg, Rfs and yield loci. MS Thesis SIUC Carbondale IL, USA, p 212.

Kazi S, Niiti VN, Doubler TW, Yuan J, lqbal MJ, Cianzio S, Lightfoot DA (2007) Registration of the Flyer by Hartwig recombinant inbred line mapping population. J Plant Reg. 1: 175-178.

Kazi S, Shultz J, Johnson J, Niiti VN, Lightfoot DA (2008) Separate loci underlie resistance to root infection and leaf scorch during soybean sudden death syndrome. Theor Appl Genet 116 (7): 967-977.

Kazi S, Shultz J, Afzal J, Hashmi R, Jasim M, Bond J, Arelli PR, Lightfoot DA (2010) Iso-lines and inbred-lines confirmed loci that underlie resistance from cultivar 'Hartwig' to three soybean cyst nematode populations. Theor Appl Genet 120 (3): 633-644.

Koenning SR, Wrather JA (2010) Suppression of soybean yield potential in the continental United States by plant diseases from 2006 to 2009. Plant Health Progress doi:10.1094/PHP-2010-122-01-RS.

Lee J-D, Kim HJ, Robbins RT, Wrather JA, Bond J, Nguyen HT, Shannon JG (2015) Reaction of soybean cyst nematode resistant plant introductions to root-knot and reniform nematodes. Plant Breed Biotech 3(4):346-354.

Meksem K, Doubler TW, Chancharoenchai K, Niiti VN, Chang SJ, Rao Arelli AP, Cregan PE, Gray LE, Gibson PT, Lightfoot DA (1999) Clustering among loci underlying soybean resistance to Fusarium solani, SDS and SCN in near-isogenic lines. Theor Appl Genet 99 (7): $1131-1142$.

McBlain BA, Fioritto RJ, St Martin SK, Calip-DuBois A, Schmitthenner AF, Cooper RL, Martin RJ (1990) Registration of 'Flyer' soybean. Crop Sci 30: 425.

Mueller DS, Li S, Hartman GL, Pedersen WL (2002) Use of aeroponic chambers and grafting to study partial resistance to Fusarium solani f. sp. glycines in soybean. Plant Dis 86: 1223-1 226.
Niiti V, Gray L, Lightfoot DA (1997) Rate-reducing resistance to Fusarium solani f.sp. phaseoli [nee: glycines] underlies field resistance to soybean sudden-death syndrome (SDS) Crop Sci. 37: 1-12. doi: 10.2135/cropsci1997.0011183X003700010023x.

Niiti VN, Johnson JE, Torto GA, Gray LE, Lightfoot DA (2001) Inoculum rate influences selection for field resistance to soybean sudden death syndrome in the greenhouse among recombinant inbred lines and cultivars. Crop Sci 41: 1726-1731.

Niblack TL, Wrather JA, Heinz RD, Donald PA (2003) Distribution and virulence phenotypes of Heterodera glycines in Missouri. Plant Dis 87: 929-932.

Robbins RT, Rakes L, Elkins CR (1994a) Reniform nematode reproduction and soybean yield of four soybean cultivars in Arkansas. J Nematol 26: 656-658.

Robbins RT, Rakes L, Elkins CR (1994b) Reproduction of the reniform nematode on thirty soybean cultivars. J Nematol 26: 659-664

Robbins RT, Rakes L (1996) Resistance to the reniform nematode in selected soybean cultivars and germplasm lines. J Nematol 28: 612615.

Robbins RT, Rakes L, Jackson LE, Dombek DG (1999) Reniform nematode resistance in selected soybean cultivars. J Nematol 31: 667-677.

Robbinson AF, Bell AA, Dighe ND, Menz MA, Nichols RL, Stelly DM (2007) Introgression of resistance to nematode Rotylenchulus reniformis into upland cotton (Gossypium hirsutum) from Gossypium longicalyx. Crop Sci 47 (5): 1865-1877.

Schmitt DP, Barker KR. 1988. Incidence of plant-parasitic nematodes in the coastal plain of North Carolina. Plant Dis 72: 107-1 10.

Shultz JL, Kazi S, Afzal JA, Bashir R, Lightfoot DA (2007) The development of $B A C$-end sequence-based microsatellite markers and placement in the physical and genetic maps of soybean. Theor Appl Genet 114: 1081-1090.

Srour A, Afzal AJ, Saini N, Blahut-Beatty L, Hemmati N, Simmonds DH, El Shemy H, Town CD, Sharma H and Lightfoot DA (2012) The receptor like kinase transgene from the Rhg $1 / R f s 2$ locus caused pleiotropic resistances to soybean cyst nematode and sudden death syndrome. BMC Genomics 13: 368-378.

Vierling RA, J. Faghihi, V.R. Ferris, and J.M. Ferris (1996). Association of RFLP markers conferring broad-based resistance to the soybean cyst nematode (Heterodera glycines). Theor Appl Genet 92: 83-86.

Webb DM, Baltazar BM, Rao-Arelli AP, Schupp J, Keim P, Clayton K, Ferreira AR, Owens T, Beavis WD (1995). QTL affecting soybean cyst-nematode resistance. Theor Appl Genet 91: 574-581 and United States Patent 5,491,081, Feb 16, 1996.

Wrather JA, Kendig SR, Anand SC (1995) Effects of tillage, cultivar and planting date on percentage of soybean leaves with symptoms of sudden death syndrome. Plant dis 79 (6): 560-562.

Wrather JA, Koenning S (2009) Effects of diseases on soybean yields in the United States 1996 to 2007. Plant Health Progress doi: 10.1094/PHP-2009-0401-01-RS.

Wubben MJ, Gavilano L, Baum TJ, Davis EL (2015) Sequence and spatiotemporal expression analysis of CLE-Motif containing genes from the reniform nematode (Rotylenchulus reniformis Linford \& Oliveira). J Nematol 47 (2): 159-165.

Yuan J, Niiti VN, Meksem K, lqbal MJ, Triwitayakorn K, Kassem MA, Davis GT, Schmidt ME, Lightfoot DA (2002) Quantitative trait loci in two soybean recombinant inbred line populations segregating for yield and disease resistance. Crop Sci 42: 271-277. 